\title{
ArF-excimer laser as a potential tool for manufacturing of biomedical polymeric devices
}

\author{
B. Stępak ${ }^{1}$, M. Kobielarz ${ }^{2 *}$, M. Gazińska ${ }^{3}$, K. Szustakiewicz ${ }^{3}$, C. Pezowicz ${ }^{2}$, A. J. Antończak ${ }^{1}$ \\ ${ }^{1}$ Laser \& Fiber Electronics Group, Faculty of Electronics, Wrocław University of Science and Technology, Wybrzeze \\ Wyspianskiego 27, 50-370 Wroclaw, Poland \\ ${ }^{2}$ Department of Mechanics, Materials and Biomedical Engineering, Faculty of Mechanical Engineering, Wrocław \\ University of Science and Technology, Wybrzeze Wyspianskiego 27, 50-370 Wroclaw, Poland \\ ${ }^{3}$ Department of Engineering and Technology of Polymers, Faculty of Chemistry, Wrocław University of Science and \\ Technology, Wybrzeze Wyspianskiego 27, 50-370 Wroclaw, Poland
}

Received 23 December 2020; accepted in revised form 7 March 2021

\begin{abstract}
The influence of excimer argon fluoride (ArF) laser cutting of poly(L-lactide) (PLLA) on its physicochemical properties was studied. The samples in the form of micro-bars of the size comparable to the width of typical vascular stents struts were fabricated in order to focus during the analysis on heat-affected zone and surfaces exposed to laser radiation and plasma. The threshold fluence and ablation rate of PLLA were measured. The ablated polymer's surface was analyzed using Scanning Electron Microscopy (SEM), and Fourier transform infrared spectroscopy (FTIR-ATR). The produced microstructures with different laser repetition rates and beam size were analyzed using differential scanning calorimetry (DSC) and gel permeation chromatography (GPC) techniques. It allowed tracking the thermal history changes of PLLA, estimating the fraction of modified polymer within micro-bars, and determining the extent of the polymer degradation by observing the molecular weight changes. In many cases, DSC revealed no significant changes in the material's thermal history; however, GPC showed that each laser fabricated sample has a low molecular weight fraction resulting from multi-pulse exposition of the micro-bar walls to UV irradiation, laser-induced plasma, UV irradiation and heat. Nevertheless, most of the micro-bars preserve their original properties within the vast majority of their volume what gives the potential to use them in biomedical applications after cleaning the components from low molecular weight fragments localized at the cut walls.
\end{abstract}

Keywords: biopolymers, biocomposites, poly(L-lactide) manufacturing, ArF excimer laser cutting, photolytic degradation, thermal degradation

\section{Introduction}

Poly(L-lactide) (PLLA) is one of the few aliphatic polymers which alone, or in combination with other polymers (usually PGA $[1,2]$ ), are used to produce bioresorbable products for biomedical applications, such as stents [3], orthopaedic implants [4] or scaffolds [5]. The main advantages of PLLA include high cytocompatibility [6], well-defined [7] and possible to controlled thermal properties [8,9], suitable strength parameters $[10,11]$ and easy processability [12], while the processing parameters significantly affect the physical and chemical properties of the polymer [6, 13-16]. For the production of biomedical products from aliphatic esters, among others, electrospinning [17], fused deposition modeling (FDM) [18], and molding [19] techniques are used and in the case of medical devices with complex geometry and small dimensions, laser micro-processing technique [20,21]. The main challenge for laser micro-machining as a technique for manufacturing polymeric medical devices is to maintain the designed geometry, mechanical and thermal properties, 
and the lack of influence on the polymer's biological properties. The laser processing techniques of thermally sensitive and biodegradable polymers for biomedical micro-devices and micro-implants in a nanosecond and femtosecond domains are intensively studied $[13,22]$. The use of femtosecond lasers to process PLLA and its copolymers seems to better justify as the reduction of pulse duration (below the electron cooling time) allows minimizing thermal damage to the material in the immediate vicinity of the laser beam irradiation [23, 24]. However, due to the high pulses repetition frequencies used in micromachining with femtosecond lasers, there is a risk of heat accumulation and diffusion, leading to the melting of material and cracks formation [25-27] as results of the decomposition of the polymer lattice. The risk of PLLA degradation under femtosecond laser micro-machining was analyzed by our group previously based on the fabrication of analogous microstructures as in current research [15]. For most of the parameter sets, femtosecond laser machining caused the change of thermal history of produced micro-bars. When the femtosecond laser's parameters are set as not to cause thermal accumulation, the effective cutting speed drops significantly with material thickness and reaches similar values to those obtained during cutting by ArF excimer laser [28]. Laser processing in the nanosecond domain is always associated with thermal effects, which is inevitable because the pulse duration is much longer than energy transfer into heat ( ps) [29]. However, in the UV spectral range, where the photon energy

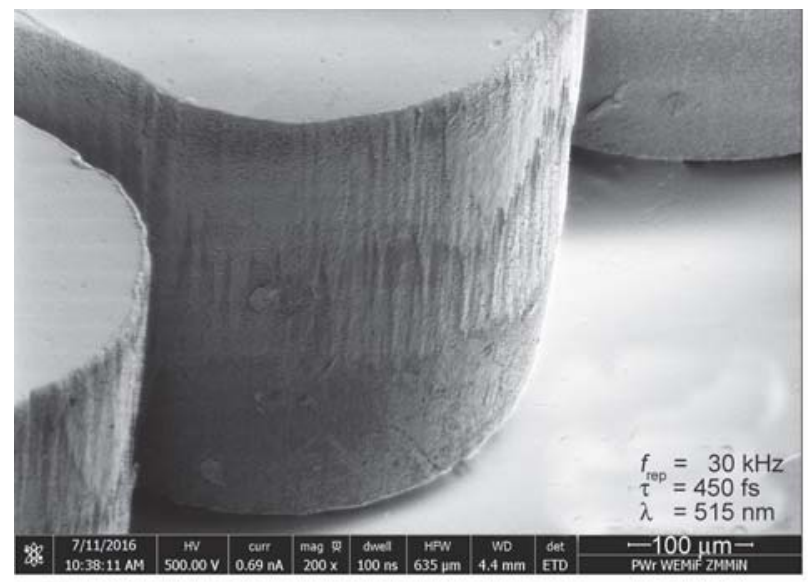

a) is high enough to directly break the polymer bonds, there is a possibility of obtaining higher process precision (Figure 1). Machining quality depends mostly on the polymer's chemical structure, and the wavelength used [30]. High photon energy can be provided by excimer lasers generating UV radiation with a typical pulse duration of 5-25 ns. The ablation of biodegradable polymers with an excimer laser found application in modification, functionalization and patterning of the surface $[23,26]$.

There is, however, a lack of reports on physicochemical changes of the produced polymeric microstructures which fact has become a motivation for this research. Moreover, the micro-machining quality achieved by our group in the first experiments using ArF excimer laser was very high what indicated a potential for biomedical devices manufacturing [28]. The study's leading aim was to define the influence of ArF laser repetition rate and laser beam dimensions on the thermal properties of fabricated microstructures and the molecular weight of the PLLA within micro-bars. Other analytical techniques and parameter sets extended the initial DSC analysis [31]. The novelty of the approach presented in this paper is based on a comprehensive investigation of in-volume laser-produced microstructures which reveals the signs of both thermal degradations connected with heat-affected zone formation and possible photodegradation. To our best knowledge, a complementary DSC and GPC analyzes of laser fabricated PLLA microstructures of the size comparable to the beam aperture has not been presented in the literature.

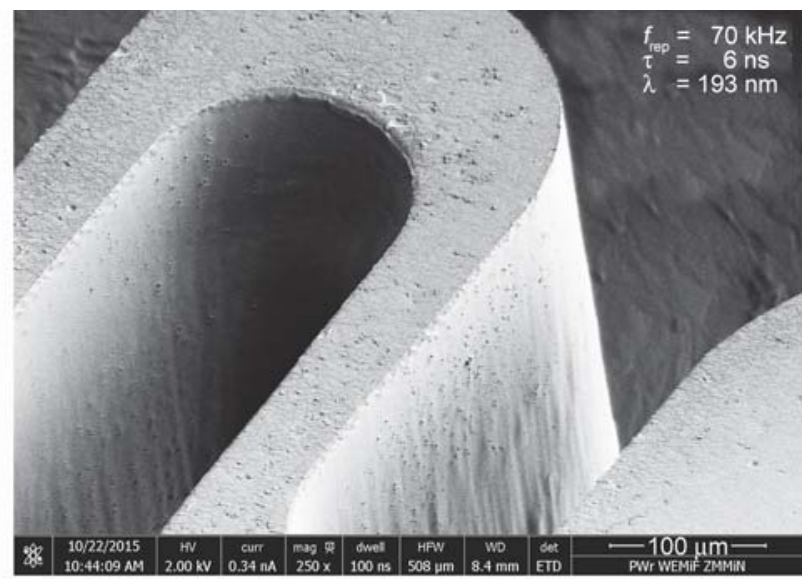

b)

Figure 1. Comparison of the quality of a coronary stent manufactured by us from polylactide: a) femtosecond laser (wavelength $\lambda=515 \mathrm{~nm}$, pulse duration $450 \mathrm{fs}$, pulse repetition rate $30 \mathrm{kHz}$, beam diameter $25 \mu \mathrm{m}$, wobble: $\Delta x=\Delta y=$ $15 \mu \mathrm{m}, 50$ repetitions), b) ArF excimer laser (wavelength $\lambda=193 \mathrm{~nm}$, pulse duration $6 \mathrm{~ns}, P R R=70 \mathrm{~Hz}$, beam diameter $50 \mu \mathrm{m}$, cutting speed $12 \mu \mathrm{m} / \mathrm{s}$ ). In both cases, total cutting time was comparable (scanning electron microscopy FEI Helios NanoLab 600i (Hillsboro, USA)). 
Additionally, the micro-bar width effect on its properties after fabrication was investigated what reveals the proportion between non-modified material and modified material in the heat-affected zone (HAZ). The spatial distribution of permanent and non-permanent changes of PLLA properties was proposed in a graphical model. The safe parameter window for the laser micro-cutting process was defined to preserve the polymer's thermal history, therefore not exceeding softening point during the process. The analysis of such narrow beams is essential, because only then the modified part of the material constitutes a large percentage of the total implant, and it allows noticing the potential risk of undesirable modification.

\section{Material and methods}

\subsection{Material}

Medical grade poly(L-lactide) (PLLA - RESOMER ${ }^{\circledR}$ L 210 S, Evonik Industry AG, Essen, Germany) was used during experiments. In order to reduce hydrolytic degradation during processing, the material was dried for 3 hours at $100^{\circ} \mathrm{C}$ under a vacuum. Then, sheets $(100 \times 100 \mathrm{~mm})$ of PLLA were prepared using a compression moulding machine at $190{ }^{\circ} \mathrm{C}$ under pressure estimated at 50 bar. Formed polymer sheets were cooled down inside the press at a rate of $20^{\circ} \mathrm{C} / \mathrm{min}$, which resulted in low crystallinity after processing $\left(X_{\mathrm{c}}<2 \%\right.$ based on DSC scan). The thickness of the obtained sheets was $450 \pm 10 \mu \mathrm{m}$.

\subsection{Laser system}

PLLA sheets were irradiated using the micro-machining system ProMaster (Optec S.A., Frameries, Belgium) consisting of an ArF excimer laser (ATLEX-300-I, ATL Lasertechnik GmbH, Wermelskirchen, Germany) operating at $193 \mathrm{~nm}$ generated pulses of 5-6 ns length, at a maximal repetition rate of $300 \mathrm{~Hz}$. The sheets were placed on the movable table with a position adjustment in the $\mathrm{X}-\mathrm{Y}$ axis with an accuracy of $\pm 1 \mu \mathrm{m}$ (Figure 2). Due to the small aperture of the beam $(6.0 \times 4.0 \mathrm{~mm} \mathrm{D} 4 \sigma)$, homogenisation was not applied.

\subsection{Sample preparation procedure and conditions}

The micro-bars (long and narrow strut-like elements) were prepared by producing parallel cuts in the PLLA sheet. The width of elements was varying between 50 and $170 \mu \mathrm{m}$ (Table 1), and the length was constant $-3 \mathrm{~mm}$ and the height was the same as polymer sheet thickness $450 \pm 10 \mu \mathrm{m}$. Cuts were made using a rectangular beam formed by the projection of the mask. In order to increase pulse overlap and speed up the process, cutting was performed in the direction parallel to the longer dimension of a beam (Figure 2a). In all experiments a constant laser fluence of $F=1.5 \mathrm{~J} / \mathrm{cm}^{2}$ was used. Different values of cutting speed and pulse repetition frequency were selected experimentally (Table 2) with a constant number of pulses per unit area were applied. After producing a series of cuts, strut-like elements were separated from the polymer sheet and then analyzed through molecular weight and thermal properties.

\subsection{Differential scanning calorimetry (DSC)}

DSC measurements were performed using differential scanning calorimeter DSC1 Mettler Toledo (Greifensee, Switzerland) equipped with Huber TC 100 intracooler. The instrument was calibrated using indium $\left(T_{\mathrm{m}}=156.6^{\circ} \mathrm{C}, \Delta H_{\mathrm{m}}=28.45 \mathrm{~J} / \mathrm{g}\right)$ and $\operatorname{zinc}\left(T_{\mathrm{m}}=\right.$ $419.7^{\circ} \mathrm{C}, \Delta H_{\mathrm{m}}=107.0 \mathrm{~J} / \mathrm{g}$ ) standards. Measurements were recorded at the temperature range of 25 $200^{\circ} \mathrm{C}$ with heating and cooling rates of $5 \mathrm{~K} / \mathrm{min}$. Each DSC sample consisted of around 20 micro-bars in order to fill up the sample pan entirely. Each curve

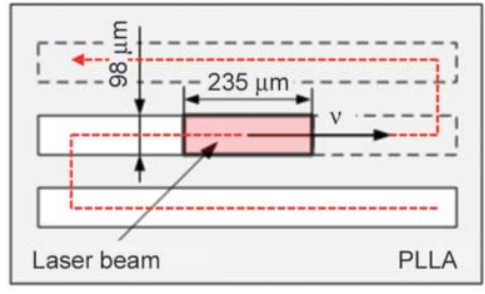

a)

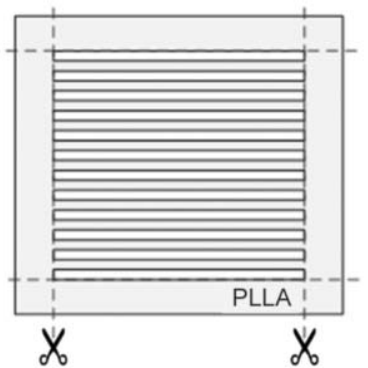

b)

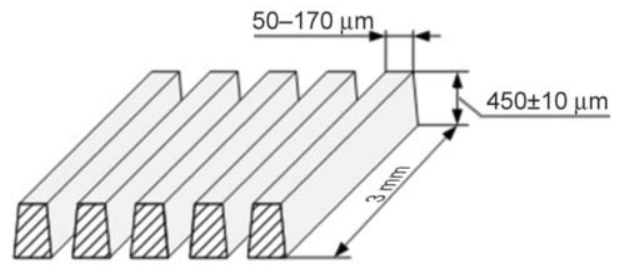

c)

Figure 2. Scheme of micro-bars preparation procedure: a) ArF laser scanning with conditions listed in Table 1, b) separation from PLLA sheet, c) dimensions and cross-section of fabricated elements. 
Table 1. List of prepared samples and the laser ArF irradiation condition.

\begin{tabular}{|c|l|c|c|c|c|c|}
\hline No. & Sample designator & $\begin{array}{c}\text { Beam width } \\
{[\boldsymbol{\mu \mathbf { m } ]}}\end{array}$ & $\begin{array}{c}\text { Frequency } \\
{[\mathbf{H z}]}\end{array}$ & $\begin{array}{c}\text { Width of cut bars } \\
{[\boldsymbol{\mu m}]}\end{array}$ & $\begin{array}{c}\text { Speed } \\
{[\boldsymbol{\mu m} / \mathbf{s}]}\end{array}$ & $\begin{array}{c}\text { Mass for DSC } \\
{[\mathbf{m g}]}\end{array}$ \\
\hline 1 & Ref & - & - & - & - & 3.30 \\
\hline 2 & $70 \mathrm{~Hz}$ w90_M3 & 147 & 70 & 90 & 40 & 2.50 \\
\hline 3 & $100 \mathrm{~Hz}$ w50_M3 & 147 & 100 & 50 & 56 & 1.95 \\
\hline 4 & 100Hz_w90_M3 & 147 & 100 & 90 & 56 & 2.60 \\
\hline 5 & 100Hz_w130_M3 & 147 & 100 & 130 & 56 & 2.99 \\
\hline 6 & 100Hz_w170_M3 & 147 & 100 & 170 & 56 & 3.06 \\
\hline 7 & 50Hz_w50_M2 & 98 & 50 & 50 & 30 & 2.66 \\
\hline 8 & $70 \mathrm{~Hz}$ w50_M2 & 98 & 70 & 50 & 40 & 2.50 \\
\hline 9 & $70 \mathrm{~Hz}$ w90_M2 & 98 & 70 & 90 & 40 & 3.00 \\
\hline 10 & 100Hz_w50_M2 & 98 & 100 & 50 & 56 & 2.90 \\
\hline 11 & 100Hz_w90_M2 & 98 & 100 & 90 & 56 & 2.86 \\
\hline 12 & 130Hz_w90_M2 & 98 & 130 & 90 & 70 & 1.98 \\
\hline 13 & 100Hz_w90_M1 & 48 & 100 & 90 & 56 & 3.25 \\
\hline
\end{tabular}

is representative of a series of micro-bars cut with the same parameters. Depending on the width of micro-bars, the weight of the measured samples was 1.9-4.0 mg. The recorded DSC curves were normalized to the sample mass. The evaluation of the DSC curves has been performed using $\mathrm{STAR}^{\mathrm{e}}$ software.

\subsection{Gel permeation chromatography (GPC)}

Measurements were carried out by dissolving the polymer in chloroform $\mathrm{CHCl}_{3}(1.5 \mathrm{mg} / \mathrm{ml}$ solution) at $35^{\circ} \mathrm{C}$, with the eluent flow rate at $0.7 \mathrm{ml} / \mathrm{min}$ and injection volume at $100 \mathrm{ml}$. The GPC/SEC analysis was performed using a $300 \mathrm{~mm}$ long chromatographic column with $5 \mathrm{~mm}$ particles (PLgel MIXED C, Agilent Technologies Inc., Santa Clara, USA) and a refractive index detector (HP 1047 Hewlett-Packard). To calibrate the chromatograph, we used polystyrene standards with molecular weights from 580 to 3993000 and a polydispersity within the range of $1.04 \div 1.14$ (Polymer Laboratories Ltd.). Obtained data were processed using the PL Caliber GPC software. The mass of the polymer samples for GPC analysis was $12 \pm 1 \mathrm{mg}$ per sample. Results calculated for all measurement's points (i.e., excluding peak molecular weight $M_{\mathrm{p}}$ and representing values of $\log M_{\mathrm{p}}$ ) were presented as value with mean square error (MSE [\%]).

\subsection{Fourier transform infrared spectroscopy (ATR-FTIR)}

The ATR-FTIR spectra were recorded using the FTIR Nicolet ${ }^{\text {TM }} 8700$ spectrophotometer with the Smart Orbit Diamond ATR accessory (Thermo Fisher
Scientific Inc., Waltham, USA) within the range of $700-4000 \mathrm{~cm}^{-1}$ and with a $0.48 \mathrm{~cm}^{-1}$ step.

\subsection{Microscopic images}

The samples' morphology was studied using both a Keyence VHX-5000 digital microscope (Osaka, Japan) and ion FEI Helios NanoLab 600i (Hillsboro, USA) scanning electron microscopy (SEM) or Phenom ProX Desktop SEM (Thermo Fisher Scientific Inc., Waltham, USA). The samples for SEM evaluations were coated with chromium $\sim 5 \mathrm{~nm}$.

\section{Results and discussion}

\subsection{Characteristics of PLLA ablation by ArF excimer laser}

At the beginning of the study, the ablation removal rate was investigated, and the laser-ablated craters were analyzed under the SEM microscope (Figure $3 b$ ). The determination of removal rate was useful for setting appropriate sample translation speed and laser repetition rate to cut through the PLLA sheets. The ablation threshold was determined by the plotting ablation rate versus laser fluence (optical energy density), the threshold value for (starting) PLLA removal. As presented in Figure 3, the curve in a horizontal logarithmic scale can be well approximated by a straight line. The line and horizontal axis's crossing point determines the ablation threshold, close to $62.8 \mathrm{~mJ} / \mathrm{cm}^{2}$. The ablation rate DPP (depth per pulse) curve follows Beer-Lamber law where the material thickness needed to attenuate the incoming laser fluence down to threshold fluence increases logarithmically. In other words, this is the thickness of the 
material, which is being removed at specific fluence, as shown by Equation (1) [32]:

$$
D P P=\frac{1}{\alpha_{\mathrm{eff}}} \cdot \ln \left(\frac{F}{F_{\mathrm{th}}}\right)
$$

where $\alpha_{\text {eff }}$ is the effective linear absorption coefficient, $F$ is the incoming laser pulse fluence and $F_{\text {th }}$ is the threshold fluence for PLLA.

At $1.5 \mathrm{~J} / \mathrm{cm}^{2}$ fluence, the ablation rate was determined to be $1.19 \mu \mathrm{m} /$ pulse when five laser pulses were used to form a crater at $50 \mathrm{~Hz}$ repetition frequency. This result is not consistent with the ablation rate based on the laser cutting experiment where 410 laser pulses at $50 \mathrm{~Hz}$ repetition frequency were needed to cut through $450 \mu \mathrm{m}$ thick sample where we obtained approximately $1.1 \mu \mathrm{m} /$ pulse ablation rate. The difference in this calculation results from the excessive number of pulses that needs to be used to overcome PLLA sheet thickness fluctuations and ensure complete separation of microstructures. Additionally, during the process, the focal plane position was not corrected what could also influence the overall ablation rate. The experimental data were estimated as an effective linear absorption coefficient for the process in the studied fluence range and ablation regime $\sim 30000 \mathrm{~cm}^{-1}$. In contrast, the linear absorption coefficient at low-intensity illumination (UV/Vis spectroscopy) is typically lower by one order of magnitude for PLLA. For the practical output of the investigation, we calculated exemplary volumetric and mass ablation rates collected in Table 2.

The ablated craters at $1.5 \mathrm{~J} / \mathrm{cm}^{2}$ laser fluence were investigated by FITR-ATR technique. In Figure 4, two fragmentary infrared spectra recorded for reference PLLA sample and laser-ablated PLLA sample were presented. After the laser ablation, a decrease of the band's intensity at $921 \mathrm{~cm}^{-1}$ related to $\mathrm{rCH}_{3}+v \mathrm{CC}$ vibrations typical for the crystalline phase of PLLA was observed [33]. The vanishing of this band is a characteristic sign of total material amorphisation. The reference sample may have some crystalline domain located close to the surface being a residuum of the polymer sheet moulding process. However, the base PLLA material's overall crystallinity was estimated to be less than $2 \%$ [6]. This conclusion is consistent with microscopic observations where exceeding of melting temperature on the surface was suggested.

Furthermore, additional low-intensity bands can be observed which are not characteristic of PLLA material. These changes can be related to the thermal and photochemical degradation of PLLA at the surface. The bands at 811 and $1649 \mathrm{~cm}^{-1}$ appearing only for laser ablated surface suggest the formation of

Table 2. Exemplary of PLLA removal rates calculated on experimental data.

\begin{tabular}{|c|c|c|c|c|c|}
\hline $\begin{array}{c}\text { Beam width } \\
{[\boldsymbol{\mu \mathbf { m } ]}}\end{array}$ & $\begin{array}{c}\text { Beam length } \\
{[\boldsymbol{\mu \mathbf { m } ]}}\end{array}$ & $\begin{array}{c}\text { Pulse repetition rate } \\
{[\mathbf{H z}]}\end{array}$ & $\begin{array}{c}\text { Cutting speed } \\
{[\boldsymbol{\mu \mathbf { m } / \mathbf { s } ]}}\end{array}$ & $\begin{array}{c}\text { Ablation rate } \\
{\left[\mathbf{m m}^{\mathbf{3}} / \mathbf{m i n}\right]}\end{array}$ & $\begin{array}{c}\text { Ablation rate } \\
{[\mathbf{m g} / \mathbf{m i n}]}\end{array}$ \\
\hline 147 & 235 & 100 & 56 & 0.22 & 0.31 \\
\hline 98 & 235 & 130 & 70 & 0.19 & 0.26 \\
\hline 98 & 235 & 100 & 56 & 0.15 & 0.21 \\
\hline 98 & 235 & 70 & 40 & 0.11 & 0.15 \\
\hline
\end{tabular}

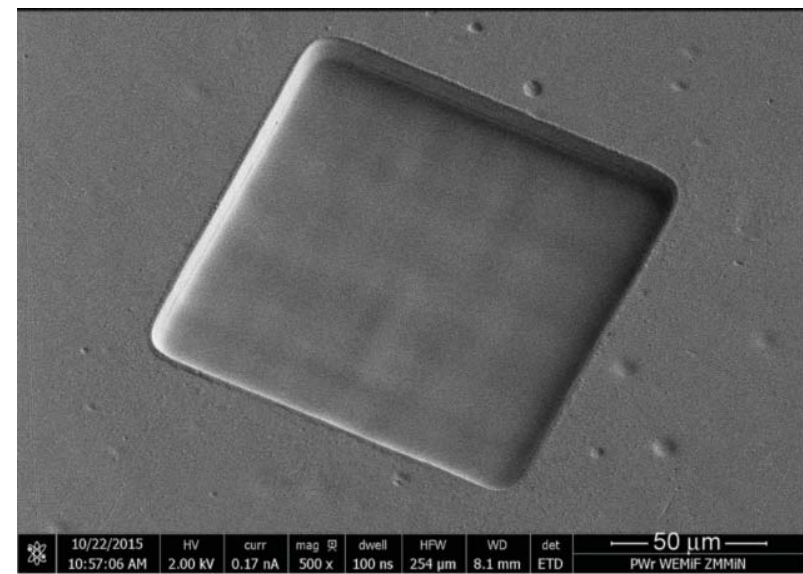

a)

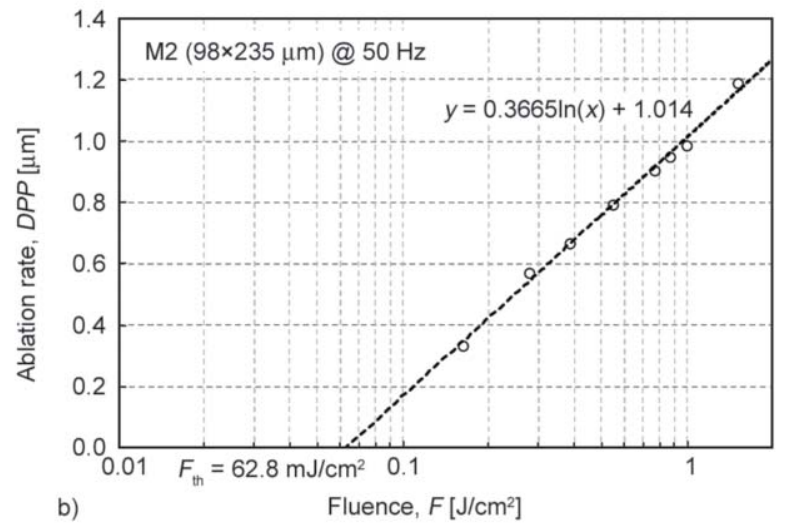

Figure 3. a) PLLA ablation rate in function of laser pulse fluence and b) SEM images of the crater formed by five pulses at $1.5 \mathrm{~J} / \mathrm{cm}^{2}$ (scanning electron microscope FEI Helios NanoLab 600i (Hillsboro, USA)). 


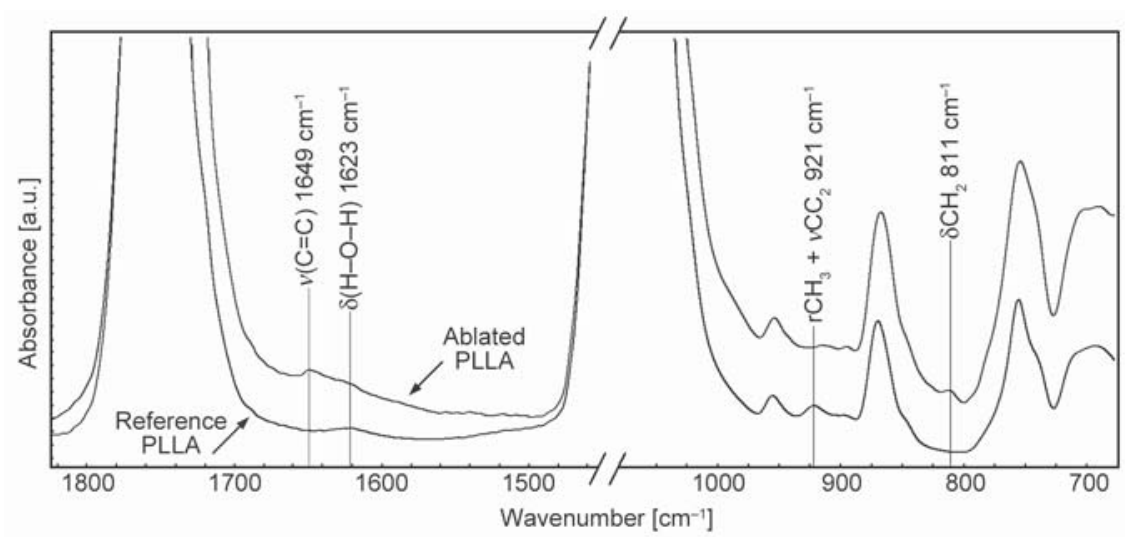

Figure 4. FTIR-ATR spectra of the reference and laser-ablated PLLA sheets.

$-\mathrm{C}=\mathrm{CH}_{2}$ vinyl groups $[16,34]$. The bands have very low intensity and are located close to the surface because the ATR technique measures only $1-3 \mu \mathrm{m}$ layer. The increase of absorption band intensity in $1500-1600 \mathrm{~cm}^{-1}$ spectral region can be attributed to water's appearance in the samples $\delta(\mathrm{H}-\mathrm{O}-\mathrm{H})$ at $1623 \mathrm{~cm}^{-1}$ [35].

Beside laser radiation itself, laser-induced plasma modifies PLLA at the edges inside the crater during the process that may cause additional polymer degradation. Further analyzes aim to investigate the extent of this modification and its spatial distribution within laser fabricated micro-bars. The selected samples are shown in Figure 5. There are four samples having bars with different thickness produced by cutting with different laser parameters. After separation from polymer sheet micro-bars were placed in DSC crucibles or dissolved for GPC analysis.

\subsection{The analysis of molecular weight distribution within the laser cut micro-bars based on GPC}

By way of introduction, generally, laser processes can be classified as non-thermal (photochemical), thermal (photothermal), or mixed (photophysical) when both interactions coincide with the predominance of one or the other. Primarily, each interaction of the laser with matter is non-thermal, and the extent of

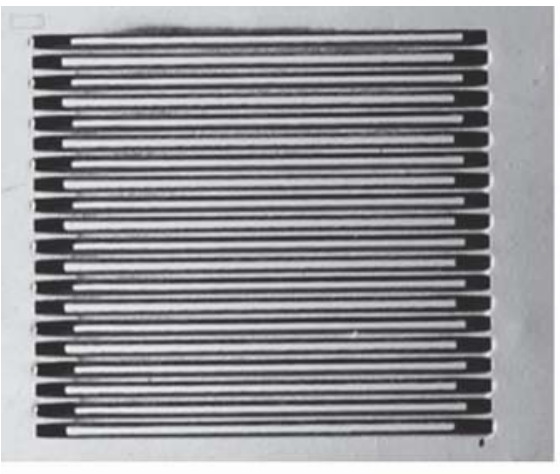

50Hz_w50_M2

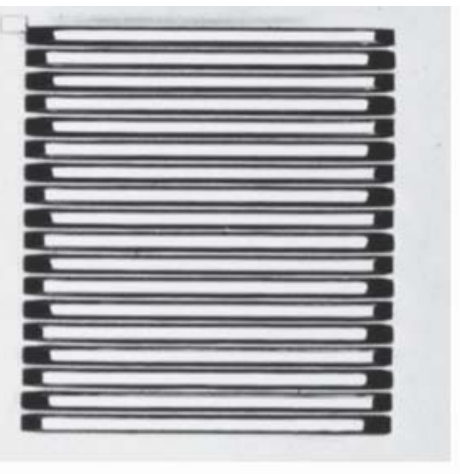

100Hz_w50_M3

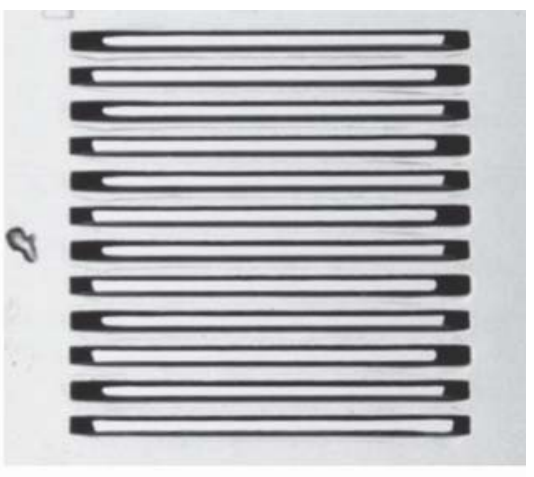

$100 \mathrm{~Hz} \_$w130_M3

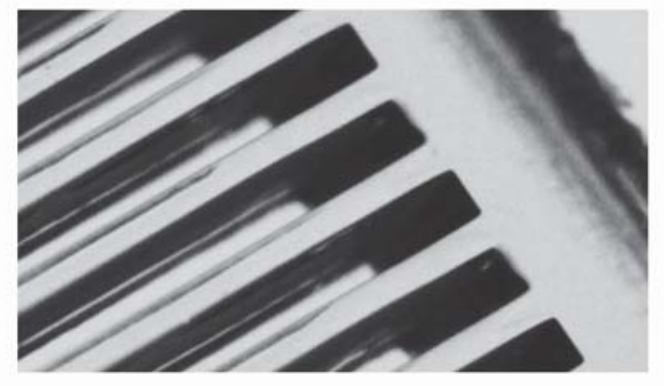

70Hz_w90_M3

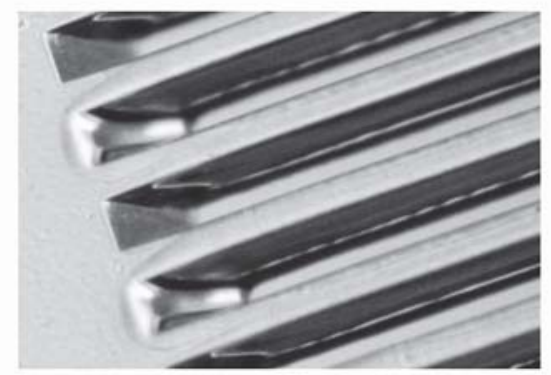

100Hz_w90_M3

Figure 5. Microscopic images of the selected samples presented micro-bars at different width prepared with different laser parameters. The cut-off micro-bars were investigated in DSC and GPC experiment. The total length of micro-bars in all images is $3 \mathrm{~mm}$. 
conversion of the excitation energy into heat depends on the dynamics of the process, which is considered thermally activated when the time necessary to achieve thermodynamic equilibrium through the interaction of material particles is shorter than the rate of their excitation [36]. In terms of linear absorption, the influence of laser radiation on polymers is characterized by two main mechanisms. When the photon energy is high enough to break bonds directly within the macroparticle ( $\mathrm{a}$ few $\mathrm{eV}$ ), the irradiated polymer dissociates by photolytic means. Otherwise, depending on the frequency of radiation, higher energy states are induced either within the electronic subnetwork (mainly the UV band) or as a result of a direct photon-phonon coupling (middle infrared (MIR) range) directly by ion polarization [37]. Except for modifying materials with a $\mathrm{CO}_{2}$ laser, any laser treatment entails inevitable photolytic degradation. The only thing we can limit is the thermal factor. In part, this fact results in the pursuit of micro-machining of materials using lasers with ultrashort pulse duration, where, as long as the process is appropriately controlled thermodegradation resulting from the accumulation of residual process heat is minimal. During the optimization of PLLA cutting with the use of the ArF laser, we noticed a great potential resulting from both the high quality of the structures produced by this method (Figure 1) and the acceptable performance (comparable with the use of a femtosecond laser [28]) despite the low pulse repetition frequency (to reduce the thermal factor limited to $50-100 \mathrm{~Hz}$ ). It was even more important to analyze how this material degrades during ArF laser treatment and what nature of degradation prevails.

Considering the above, the experiment of PLLA cutting with the ArF laser was planned so that both degradation factors could be assessed separately. Thus, the differential curves of the molecular weight distribution function (MWD) of the analyzed cases were presented separately for:

i. cutting with different pulse repetition rate (Figure 6),

ii. cutting with a different aperture of the laser beam (the size of the micro mask used) (Figure 7) and

iii. cutting micro-bars of different widths (Figure 8). All analyzed cases were related to the sheet of unmodified PLLA material (Ref). For the reference sample, the MWD was unimodal, symmetrical and close to the normal distribution (Figure 6-8). The values for the number-average molecular weight $M_{\mathrm{n}}$ and weight-average molecular weight $M_{\mathrm{w}}$, as well as the polydispersity index $(P D I)$ for individual cases, are summarized in Tables 3-5.

i. Cutting the polymer using different pulse repetition rate $(P R R)$ allowed, first of all, to study the influence of the thermal load of the material on degradation. A higher $P R R$ increases the accumulation of residual heat from individual pulses. Thus the material has a chance to heat up to a higher temperature. Although the material reached different temperatures for different $P R R$ - which was later confirmed by the DSC technique (the ageing relaxation peak remained for low $P R R$ ) - an almost identical image of degradation was obtained for all analyzed frequencies (Figure 6).

All analyzed curves relating to laser micro-bars cutting showed a bimodal distribution and are strongly asymmetric. Compared to reference PLLA material number-average molecular weight $\mathrm{Mn}$ and weightaverage molecular weight $\mathrm{Mw}$ significantly decreased (Mn reduced at least an order of magnitude). This feature is also characteristic of solution casting and hot-melt extrusion [38]. The polydispersity index also increased by order of magnitude. These indicated a significant degradation. Analysing the distribution,

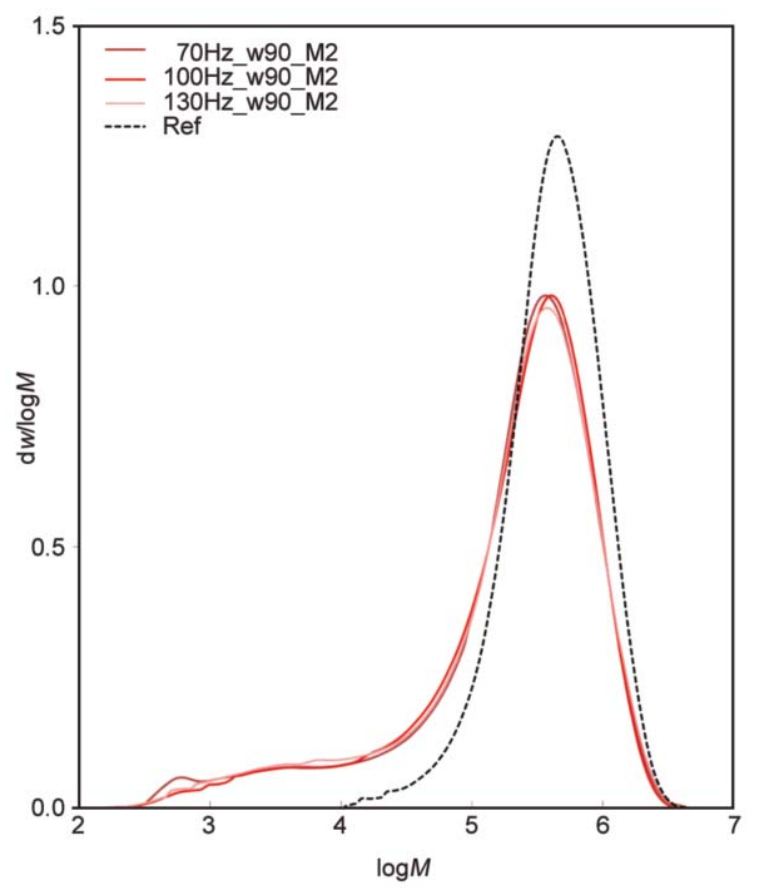

Figure 6. Molecular weight distribution for PLLA microbars of constant widths $(90 \mu \mathrm{m})$ at different laser repetition frequencies and constant beam width $(98 \mu \mathrm{m})$. 
Table 3. The number-average molecular weight $M_{\mathrm{n}}$, weight-average molecular weight $M_{\mathrm{w}}$, peak molecular weight $M_{\mathrm{p}}$ and representing values of $\log M_{\mathrm{p}}$, as well as the polydispersity index (PDI) for PLLA micro-bars of constant widths $(90 \mu \mathrm{m})$ at different laser repetition frequencies and constant beam width $(98 \mu \mathrm{m})$.

\begin{tabular}{|c|c|c|c|c|c|}
\hline Sample designator & $\begin{array}{c}M_{\mathbf{n}} \\
{[\mathrm{g} / \mathrm{mol}]} \\
(\mathrm{MSE}[\%])\end{array}$ & $\begin{array}{c}M_{\mathrm{w}} \\
{[\mathrm{g} / \mathrm{mol}]} \\
(\mathrm{MSE}[\%])\end{array}$ & $\begin{array}{c}M_{\mathrm{p}} \\
{[\mathrm{g} / \mathrm{mol}]}\end{array}$ & $\log M_{p}$ & $\begin{array}{c}P D I\left(M_{\mathrm{w}} / M_{\mathrm{n}}\right) \\
(\operatorname{MSE}[\%])\end{array}$ \\
\hline Ref & $\begin{array}{c}263153 \\
(3.7)\end{array}$ & $\begin{array}{c}555595 \\
(3.1)\end{array}$ & 457405 & 5.66 & $\begin{array}{c}2.1 \\
(2.7)\end{array}$ \\
\hline 70Hz_w90_M2 & $\begin{array}{l}15965 \\
(4.4)\end{array}$ & $\begin{array}{c}411059 \\
(1.3)\end{array}$ & 360959 & 5.57 & $\begin{array}{l}25.8 \\
(3.1)\end{array}$ \\
\hline 100Hz_w90_M2 & $\begin{array}{l}16654 \\
(4.6)\end{array}$ & $\begin{array}{c}408174 \\
(0.9)\end{array}$ & 398588 & 5.59 & $\begin{array}{l}20.8 \\
(4.6)\end{array}$ \\
\hline 130Hz_w90_M2 & $\begin{array}{l}16486 \\
(5.8)\end{array}$ & $\begin{array}{c}403493 \\
(2.3)\end{array}$ & 370211 & 5.56 & $\begin{array}{l}24.5 \\
(3.8)\end{array}$ \\
\hline
\end{tabular}

we can distinguish two factors however here - the 'tail' formed for the fraction with low molecular weight $\left(\log M_{\mathrm{w}}<4.5\right)$ and the shift of the main fraction $\left(\log M_{\mathrm{w}}>4.5\right)$ towards lower values. Relating presented results to our previous research can be assumed that the shift of the main fraction is mainly the result of photolytic degradation, but the 'tail' formation for low $M_{\mathrm{w}}$ values is the reflection of strong thermal and plasma-driven, degradation occurred only in a very narrow zone tangent to the ablation area. The modification of PLLA with a $\mathrm{CO}_{2}$ laser [16] led strictly to thermal impact on the material visible on GPS curve as characteristic 'tail' formed in low $M_{\mathrm{w}}$ range. While modification with ultrashort femtosecond pulses, where the material was not heated [15], resulted in pure shifting of total GPC curve toward lower $M_{\mathrm{w}}$ values. The degradation process of PLLA in femtosecond pulse regime was attributed to photolytic phenomena. Here, the material has exceeded the temperature of thermal degradation in a very narrow zone. The remaining changes observed may result from photolysis. Indeed, the radiation's penetration depth for this wavelength is very shallow $(\sim \mu \mathrm{m})$, which means that few photons reach the depth. However, each of them has enough energy $(6.4 \mathrm{eV})$ to break the selected bonds. Besides, the temperature that accompanies the process reduces the cage effect [39], favouring the quantum efficiency of breaking bonds. Furthermore, multiple microbar exposure to wideband UV - VIS plasma radiation can also be a factor causing photodegradation, especially in $200-300 \mathrm{~nm}$ spectral range.

ii. As in the previous case, cutting micro-bars using different apertures of the laser beam also mainly affects the process's temperature. The larger beam diameter (or aperture) induces more significant heat loss into the material. The material must heat up more because the cross-section of the 'channel' through which the heat is transported deeper into the material is larger. This has been reported repeatedly on various lasers. For this reason, the same result was noted as in the case of tests as a function of different $P R R$ - Figure 7.

iii. The situation is different for cutting micro-bars as a function of their width - Figure 8. Compared to reference PLLA material number-average molecular weight $M_{\mathrm{n}}$ and weight-average molecular weight $M_{\mathrm{w}}$ significantly and successively decreases (the reduction of $M_{\mathrm{n}}$ exceeds an order of magnitude) as the micro-bars' width decreases.

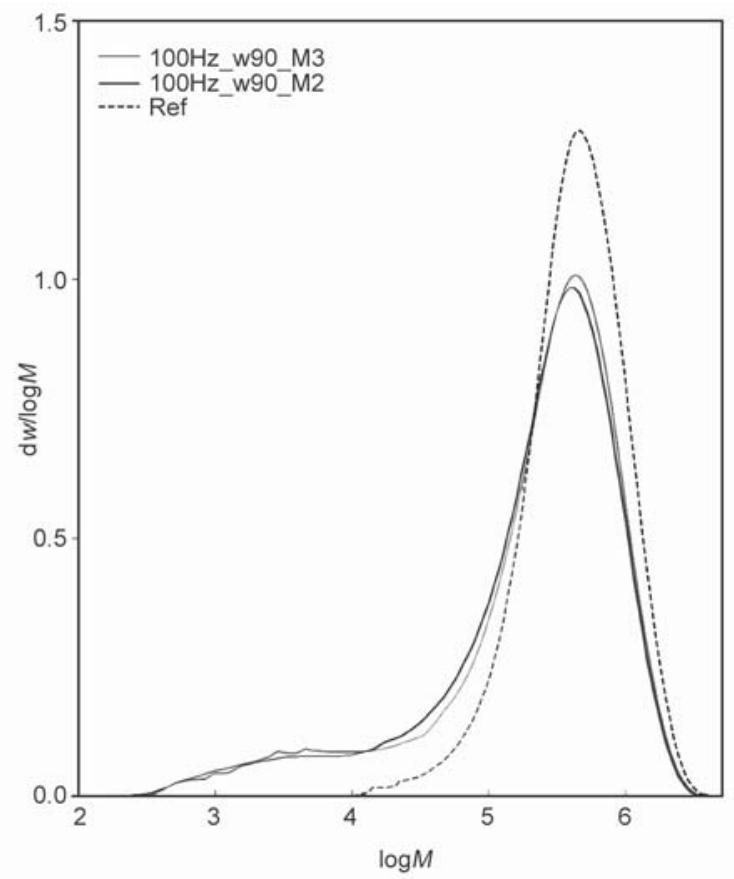

Figure 7. Molecular weight distribution for PLLA microbars of constant widths $(90 \mu \mathrm{m})$ at different beam width and constant laser repetition frequencies $(100 \mathrm{~Hz})$. 
Table 4. The number-average molecular weight $M_{\mathrm{n}}$, weight-average molecular weight $M_{\mathrm{w}}$, peak molecular weight $M_{\mathrm{p}}$ and representing values of $\log M_{\mathrm{p}}$, as well as the polydispersity index (PDI) for PLLA micro-bars of constant widths $(90 \mu \mathrm{m})$ at different beam width and constant laser repetition frequencies $(100 \mathrm{~Hz})$.

\begin{tabular}{|l|c|c|c|c|c|}
\hline Sample designator & $\begin{array}{c}\boldsymbol{M}_{\mathbf{n}} \\
{[\mathbf{g} / \mathbf{m o l}]} \\
\text { (MSE [\%]) }\end{array}$ & $\begin{array}{c}\boldsymbol{M}_{\mathbf{w}} \\
\text { [g/mol] } \\
\text { (MSE [\%]) }\end{array}$ & $\begin{array}{c}\boldsymbol{M}_{\mathbf{p}} \\
{[\mathbf{g} / \mathbf{m o l}]}\end{array}$ & $\log _{\mathbf{p}}$ & $\begin{array}{c}\boldsymbol{P D I}\left(\boldsymbol{M}_{\mathbf{w}} / \boldsymbol{M}_{\mathbf{n}}\right) \\
(\mathbf{M S E}[\%])\end{array}$ \\
\hline Ref & $\begin{array}{c}263153 \\
(3.7)\end{array}$ & $\begin{array}{c}555595 \\
(3.1)\end{array}$ & 457405 & 5.66 & $\begin{array}{c}2.1 \\
(2.7)\end{array}$ \\
\hline 100Hz_w90_M3 & $\begin{array}{c}18376 \\
(3.9)\end{array}$ & $\begin{array}{c}413059 \\
(2.8)\end{array}$ & 428389 & 5.63 & $\begin{array}{c}21.3 \\
(2.7)\end{array}$ \\
\hline 100Hz_w90_M2 & $\begin{array}{c}19654 \\
(4.6)\end{array}$ & $\begin{array}{c}408174 \\
(0.9)\end{array}$ & 398588 & 5.59 & $\begin{array}{c}20.8 \\
(4.6)\end{array}$ \\
\hline
\end{tabular}

This part of the experiment is the most difficult to analyze for two reasons. First, the smaller the width

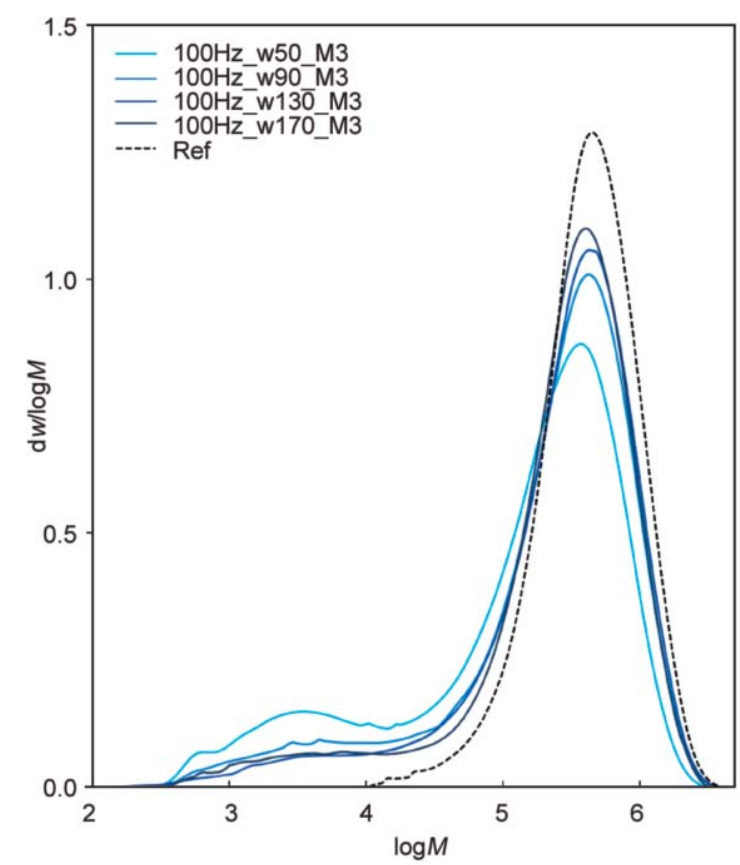

Figure 8. Molecular weight distribution for PLLA microbars of different widths at constant process parameters, i.e. beam width $(147 \mu \mathrm{m})$ and frequency $(100 \mathrm{~Hz})$. of the element to be cut, the greater the percentage of the volume in which degradation occurs related to the element's total volume to be cut. This, for obvious reasons, may increase the observed degradation. Secondly, the decreasing dimensions of the cut out element favour heat accumulation (the same energy losses in a smaller space), and thus causes an increase in temperature. These factors cannot be separated objectively. Therefore, one can only make a general conclusion that the risk of stronger degradation is higher for narrower structures.

\subsection{Thermal properties (DSC)}

The polymer modification caused by heat and UV loads during laser micro-machining can be evaluated based on DSC measurements. The melting of semicrystalline polymer, changes in crystallinity degree, reorganization of the crystal structure can be caused by conducted heat as a form of absorbed laser energy. The observed changes in the thermal properties of PLLA can steam from heat and thermal degradation and photodegradation. The laser beam's action can also affect the thermal and thermomechanical history of polymer and, in the further applications, hydrolytic degradation behavior, critical in biomedical

Table 5. The number-average molecular weight $M_{\mathrm{n}}$, weight-average molecular weight $M_{\mathrm{w}}$, peak molecular weight $M_{\mathrm{p}}$ and representing values of $\log M_{\mathrm{p}}$, as well as the polydispersity index (PDI) for PLLA micro-bars of different widths at constant process parameters, i.e. beam width $(147 \mu \mathrm{m})$ and frequency $(100 \mathrm{~Hz})$.

\begin{tabular}{|c|c|c|c|c|c|}
\hline Sample designator & $\begin{array}{c}M_{\mathrm{n}} \\
{[\mathrm{g} / \mathrm{mol}]} \\
(\mathrm{MSE}[\%])\end{array}$ & $\begin{array}{c}M_{\mathrm{w}} \\
{[\mathrm{g} / \mathrm{mol}]} \\
(\mathrm{MSE}[\%])\end{array}$ & $\begin{array}{c}M_{\mathrm{p}} \\
{[\mathrm{g} / \mathrm{mol}]}\end{array}$ & $\log M_{p}$ & $\begin{array}{c}P D I\left(M_{\mathrm{w}} / M_{\mathrm{n}}\right) \\
(\mathrm{MSE}[\%])\end{array}$ \\
\hline Ref & $\begin{array}{c}263153 \\
(3.7)\end{array}$ & $\begin{array}{c}555595 \\
(3.1)\end{array}$ & 457405 & 5.66 & $\begin{array}{c}2.1 \\
(2.7)\end{array}$ \\
\hline 100Hz_w50_M3 & $\begin{array}{l}11809 \\
(5.3)\end{array}$ & $\begin{array}{c}325527 \\
(2.8)\end{array}$ & 368216 & 5.57 & $\begin{array}{l}27.6 \\
(2.6)\end{array}$ \\
\hline 100Hz_w90_M3 & $\begin{array}{l}18376 \\
(3.9)\end{array}$ & $\begin{array}{c}413059 \\
(2.8)\end{array}$ & 428389 & 5.63 & $\begin{array}{l}21.3 \\
(2.9)\end{array}$ \\
\hline 100Hz_w130_M3 & $\begin{array}{l}26084 \\
(3.0)\end{array}$ & $\begin{array}{c}440124 \\
(2.5)\end{array}$ & 429905 & 5.62 & $\begin{array}{l}16.7 \\
(2.1)\end{array}$ \\
\hline 100Hz_w170_M3 & $\begin{array}{l}26844 \\
(4.2)\end{array}$ & $\begin{array}{c}455693 \\
(3.5)\end{array}$ & 407311 & 5.60 & $\begin{array}{l}17.0 \\
(1.8)\end{array}$ \\
\hline
\end{tabular}


applications. The first heating DSC curves of reference and laser-cut PLLA samples are presented in Figures 9, 10 and 11a. On the first heating DSC curve, glass transition and exo- and endothermic effects can be observed related to the polymer's phase transitions. The glass transition temperature $T_{\mathrm{g}}$, set as an inflection point, of the reference sample, was found at $65.4{ }^{\circ} \mathrm{C}$. An endothermic effect overlapping on the high-temperature side of glass transition is connected with the relaxation process, and relaxation enthalpy depends on aging time and temperature [40]. The most prominent changes in thermal properties of laser cut PLLA samples concern glass transition. The $T_{\mathrm{g}}$ values estimated from second heating DSC curves decreases about $3.7 \div 8.8^{\circ} \mathrm{C}$ depending on cutting parameters comparing to reference PLLA $\left(62.1^{\circ} \mathrm{C}\right)$ (Table 6, Figure 11b). At higher temperatures, at the range of $90 \div 140^{\circ} \mathrm{C}$, an exothermic peak connected with cold crystallization is present. The maximum of cold crystallization peak for reference PLLA is located at $109.3^{\circ} \mathrm{C}$. Finally, above $160^{\circ} \mathrm{C}$ an endothermic effect of melting of the crystalline structure of PLLA can be observed. The small exothermic peak prior to melting peak with a maximum at $160^{\circ} \mathrm{C}$ results from $\alpha^{\prime}-\alpha$ crystal form transformation [41]. The melting point of reference PLLA was found at $T_{\mathrm{m}}=$ $179.4^{\circ} \mathrm{C}$, and for all laser cut samples, $T_{\mathrm{m}}$ is lower about cca. $2{ }^{\circ} \mathrm{C}$. Decrease of $T_{\mathrm{m}}$ and relevant decrease of $T_{\mathrm{g}}$ is a result of lowering of mean molecular weight of PLLA as a consequence of combined photo- and thermodegradation. Based on our previous results concerning $\mathrm{CO}_{2}$ laser modification of PLLA, where thermodegradation was confirmed [10, 16], we can hypothesize that observed changes in $T_{\mathrm{g}}$ and $T_{\mathrm{m}}$ are mainly due photodegradation. Changes in thermal properties of PLLA caused by $\mathrm{CO}_{2}$ laser modification and accompanying thermodegradation of amorphous PLLA were concerned to cold crystallization behavior, whereas $T_{\mathrm{g}}$ and $T_{\mathrm{m}}$ were not influenced.

Moreover, some differences between curves of samples cut with different laser parameters in the melting region, such as broadening of peak half-width and lowering of melting enthalpy, are present. Reference and laser-cut PLLA samples were amorphous as is stem from the values of melting enthalpy $\left(\Delta H_{\mathrm{m}}\right)$, cold crystallization enthalpy $\left(\Delta H_{\mathrm{cc}}\right)$ and enthalpy of $\alpha^{\prime}-\alpha$ reorganization $\left(\Delta H_{\alpha^{\prime}-\alpha}\right)$. Therefore, the laser process did not change the material's crystallinity degree in bulk, but changes in cold crystallization behavior were introduced as it can be concluded based on different traces of cold crystallization exotherms and lowering of the $\Delta H_{\mathrm{cc}}$. Based on the decrease of $\Delta H_{\mathrm{cc}}$ and $\Delta H_{\mathrm{m}}$, after the ArF laser action crystallization of PLLA is restricted.

The most visible changes introduced by laser beam comparing to reference PLLA concerned glass transition region and enthalpy relaxation effect. The enthalpy relaxation effect appears when the heating rate is faster than the cooling rate when the glass was formed, or as in the present case, when the glass was annealed below $T_{\mathrm{g}}$. With the increase of pulse repetition rate, the enthalpy of relaxation effect decreased (Figure 9). For the samples cut with $100 \mathrm{~Hz}$, the relaxation effect disappeared, and another endothermic effect was visible at higher temperatures. The enthalpy relaxation peak occurrence depended not only on the frequency but also on the combination of the parameters such as bar width, beam width, and frequency. The enthalpy relaxation effect, reflecting the material's thermal history, can be erased by heating above $T_{\mathrm{g}}$. Therefore, it can be assumed that for repetition frequency 50 and $70 \mathrm{~Hz}$ (Figure 9, 10), the PLLA bar volume that not exceeded $T_{\mathrm{g}}=65.4^{\circ} \mathrm{C}$ was presented. This region had an entire thermal history and can be considered as reference PLLA. In the case of $100 \mathrm{~Hz}$, based on the disappearance of enthalpy relaxation peak (Figure 9, 10 and 11a), we implied that the glass transition temperature exceeded the entire volume of produced elements. The exception was the sample $100 \mathrm{~Hz}$ w90_M1 cut with the narrowest beam width (Figure 10). Due to low heat accumulation, the enthalpy relaxation peak was not erased. The influence of pulse repetition rate (i), the aperture of the laser beam (ii), micro-bars width (iii) on thermal properties of PLLA were analyzed in order to optimize the combination of these parameters.

i. To evaluate the influence of the cutting frequency on the thermal properties of PLLA the first heating DSC curves of samples cut at different frequencies and two selected micro-bar widths, 50 and $90 \mu \mathrm{m}$ are depicted in Figure 10. The estimated thermal parameters, such as $T_{\mathrm{m}}$ and $\Delta H_{\mathrm{m}}$ from the first heating DSC curve and $T_{\mathrm{g}}, T_{\mathrm{m}}$ from the second heating, are presented in Table 6 . In constant beam width, considerable differences in DSC curves can be observed depending on the repetition frequency of laser pulses. For samples cut at the frequency of 50 and $70 \mathrm{~Hz}$, which corresponds to the speed of 30 and $40 \mu \mathrm{m} / \mathrm{s}$, 
a clear enthalpy relaxation effect was visible as a peak overlapping high-temperature side of glass transition, similar to the reference material. Despite the small micro-bar width, i.e., 50 and $90 \mu \mathrm{m}$ and the width of the M2 mask (98 $\mu \mathrm{m})$ - the material has retained its thermal history. The material temperature did not exceed the $T_{\mathrm{g}}$ during the cutting process. However, the $T_{\mathrm{g}}$ values estimated from the second cooling DSC scan are lower than the reference. This indicated a decrease in molecular weight due to the photodegradation process. Within this samples (50Hz_w50_M2, 70Hz_w50_M2, 70Hz_w90_M2), theses with narrower bar width $(50 \mu \mathrm{m})$ have lower values of $T_{\mathrm{g}}$ and $T_{\mathrm{m}}$ than bars with a thickness of $90 \mu \mathrm{m}$ (Table 6).

With an increase in the repetition frequency, the relaxation enthalpy value decreased, and a new weak endothermic maximum above enthalpy relaxation effect appeared. The changes in thermal properties also concern cold crystallization. The characteristic bimodal shape of cold crystallization is visible for all samples, above the temperature of $118^{\circ} \mathrm{C}$, the material crystallizes in the ordered $\alpha$ form, and below it in the imperfect $\alpha^{\prime}$ form $[4,5]$. This bimodality was due to the different growth rates of different crystal forms. The position of inflections and the proportions between the $\alpha$ and $\alpha^{\prime}$ forms are determined, among others, by the thermal history of poly(L-lactide) and the heating rate, which was constant in all experiments and set $5 \mathrm{~K} / \mathrm{min}$. With an increase in the repetition frequency the area under the exothermic effect of cold crystallization below $118^{\circ} \mathrm{C}$ corresponding to the crystallization of $\alpha^{\prime}$ form decreased in line with the increase of the area under cold crystallization exotherm above $118^{\circ} \mathrm{C}$. Thus, the enthalpy

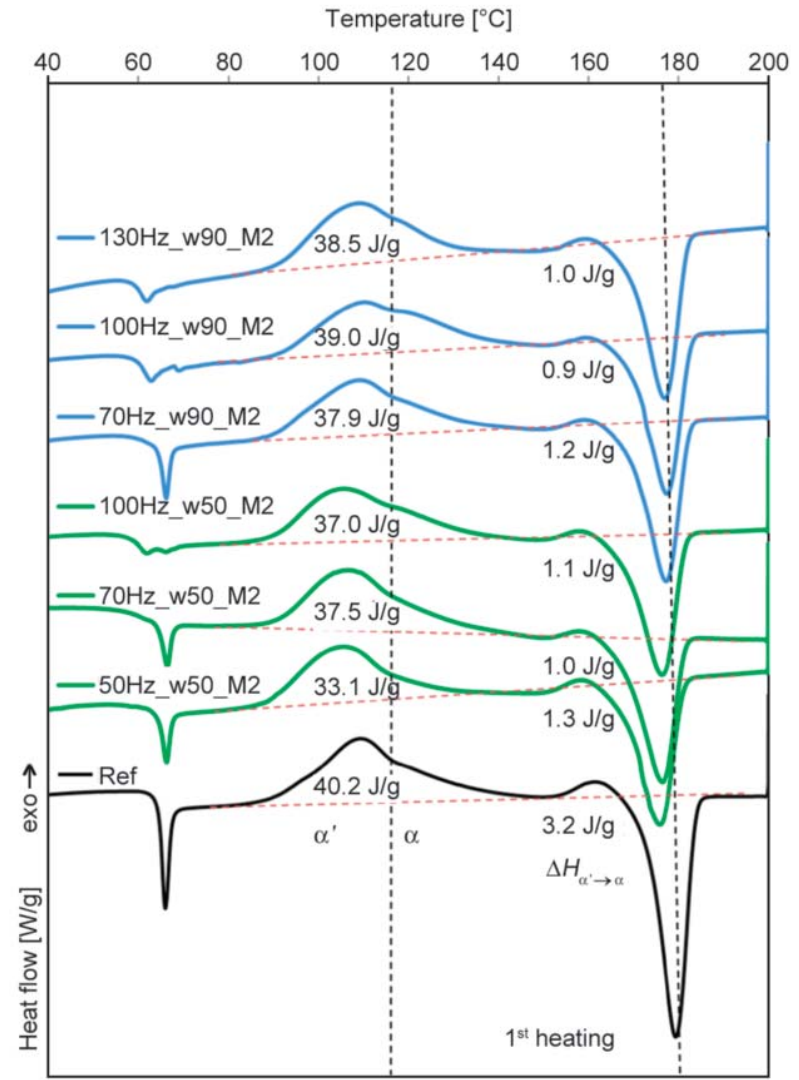

Figure 9. The first heating DSC curves of reference PLLA (black line) and PLLA bars cut with a different pulse repetition rate and two constant micro-bars widths, $90 \mu \mathrm{m}$ (blue lines) and $50 \mu \mathrm{m}$ (green lines).

of small exothermic effect visible with a maximum at approx. $160^{\circ} \mathrm{C}$, corresponding to the reorganization of conformationally disordered $\alpha^{\prime}$-crystals into stable $\alpha$-crystals [41], decreased.

Melting temperature of micro-bars with a width of $50 \mu \mathrm{m}$ was lower than of $90 \mu \mathrm{m}$. The decrease of $T_{\mathrm{m}}$ compared to reference was only about $2^{\circ} \mathrm{C}$ but was

Table 6. The selected phase transition temperatures estimated from the first and second heating DSC scans and melting enthalpy of the reference and laser cut PLLA samples.

\begin{tabular}{|c|c|c|c|c|}
\hline Sample & 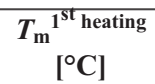 & $\begin{array}{c}\Delta \boldsymbol{H}_{\mathrm{m}}{ }^{\text {st heating }} \\
{\left[{ }^{\circ} \mathbf{C}\right]}\end{array}$ & $\begin{array}{c}T_{\mathrm{g}}{ }^{2^{\text {nd }}} \text { heating } \\
{\left[{ }^{\circ} \mathrm{C}\right]}\end{array}$ & 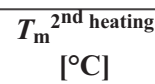 \\
\hline Ref & 179.4 & 43.6 & 62.1 & 178.8 \\
\hline 100Hz_w50_M2 & 176.3 & 32.4 & 54.9 & 175.6 \\
\hline 70Hz_w50_M2 & 176.4 & 32.8 & 55.1 & 175.6 \\
\hline 50Hz_w50_M2 & 175.9 & 32.4 & 55.1 & 175.4 \\
\hline 130Hz_w90_M2 & 177.0 & 35.0 & 56.4 & 176.4 \\
\hline 100Hz_w90_M2 & 177.4 & 34.8 & 57.1 & 176.6 \\
\hline 70Hz_w90_M2 & 177.3 & 35.1 & 57.4 & 176.5 \\
\hline 100Hz_w50_M3 & 177.1 & 34.2 & 54.9 & 176.3 \\
\hline 100Hz_w90_M3 & 176.8 & 33.5 & 54.6 & 176.3 \\
\hline 100Hz_w90_M1 & 177.0 & 35.4 & 55.0 & 176.8 \\
\hline 70Hz_w90_M3 & 177.0 & 34.7 & 56.6 & 176.8 \\
\hline
\end{tabular}


accompanied by a relevant broadening of the melting temperature range.

Based on the DSC curves' observation in Figure 10 and data presented in Table 6, it can be concluded that the repetition frequency was a crucial parameter in terms of heating of the micro-bars. Lowering its value from 100 to $70 \mathrm{~Hz}$ can significantly benefit in minimizing the effect of heat on the material during laser cutting. However, this is a reduction in process efficiency due to a speed reduction of $28.5 \%$. It can be assumed that for samples $50 \mathrm{~Hz}_{-} w 50 \_\mathrm{M} 2$, 70Hz_w50_M2, 70Hz_w90_M2, the material did not exceed the glass transition temperature within the HAZ/LAZ. A clear improvement in quality can be seen between Figure 6, were the cutting effect with 100 and $70 \mathrm{~Hz}$ is presented. Despite a lower repetition rate, a small amount of melted material has erupted onto the surface along the cut edge.

On the other hand, repetition frequency has no significant effect for a given beam thickness on lowering characteristic temperatures, possibly decreasing photodegradation. Based on data presented in Table 6 can be concluded that $T_{\mathrm{m}}$ and $T_{\mathrm{g}}$ 's values do not depend on the repetition frequency at the constant beam width. The repetition frequency does not influence the material's photothermal degradation and the decrease in $T_{\mathrm{m}}$ and $T_{\mathrm{g}}$ value of PLLA.

Based on lower values of $\Delta H_{\mathrm{cc}}$ and $\Delta H_{\mathrm{m}}$ of laser cut samples, crystallization of laser cut samples is restricted. It can be concluded that restricted crystallization of PLLA results from photodegradation.

ii. The influence of beam widths on thermal properties of PLLA was also investigated, DSC curves of selected samples cut with the different mask are combined in Figure 10, and the estimated thermal properties are collected in Table 6 . For the frequency of $100 \mathrm{~Hz}$ and a micro-bar width of $90 \mu \mathrm{m}$, cutting with the narrowest mask causes that the enthalpy relaxation peak overlapping on the high-temperature side of glass transition was still visible on the DSC curve. At these parameters, laser operation did not entirely erase the thermomechanical history of the material. The material was not heated above the $T_{\mathrm{g}}$ in its entire volume. It can be explained by low heat accumulation when using the narrowest mask. The DSC curve for this sample $(100 \mathrm{~Hz}$ w 90 _M1 $)$ is similar to the reference. The DSC curves for wider laser beam did not show an enthalpy relaxation peak, and there are also differences at the cold crystallization range. The cold crystallization enthalpies' values were lower than the reference value, and the share of crystallization above $118^{\circ} \mathrm{C}$ was greater. At the same frequency $(100 \mathrm{~Hz})$ but for a narrower bar width $(50 \mu \mathrm{m})$ the changes were even more intense, an additional endothermic peak appeared above the glass transition.

At a lower cutting frequency $(70 \mathrm{~Hz})$ and a microbar width of $90 \mu \mathrm{m}$, changes at the glass transition compared to the reference were smaller for samples cut with the $98 \mu \mathrm{m}$ mask. With a cut frequency of $70 \mathrm{~Hz}$, the enthalpy relaxation peak remained not erased with the narrower mask used $(98 \mu \mathrm{m})$, analogous to the frequency of $100 \mathrm{~Hz}$ and the mask width of $48 \mu \mathrm{m}\left(100 \mathrm{~Hz} \_w 90 \_\mathrm{M} 1\right)$. Summarizing, the higher the frequencies, the width of the mask at which the changes were the smallest must be narrower. For a given cutting frequency, the width of the mask should be selected experimentally.

Similarly like the frequency, the beam's width affects the material's heating but does not affect the photodegradation process and the decrease in $T_{\mathrm{g}}, T_{\mathrm{m}}$, $\Delta H_{\mathrm{cc}}$ and $\Delta H_{\mathrm{m}}$

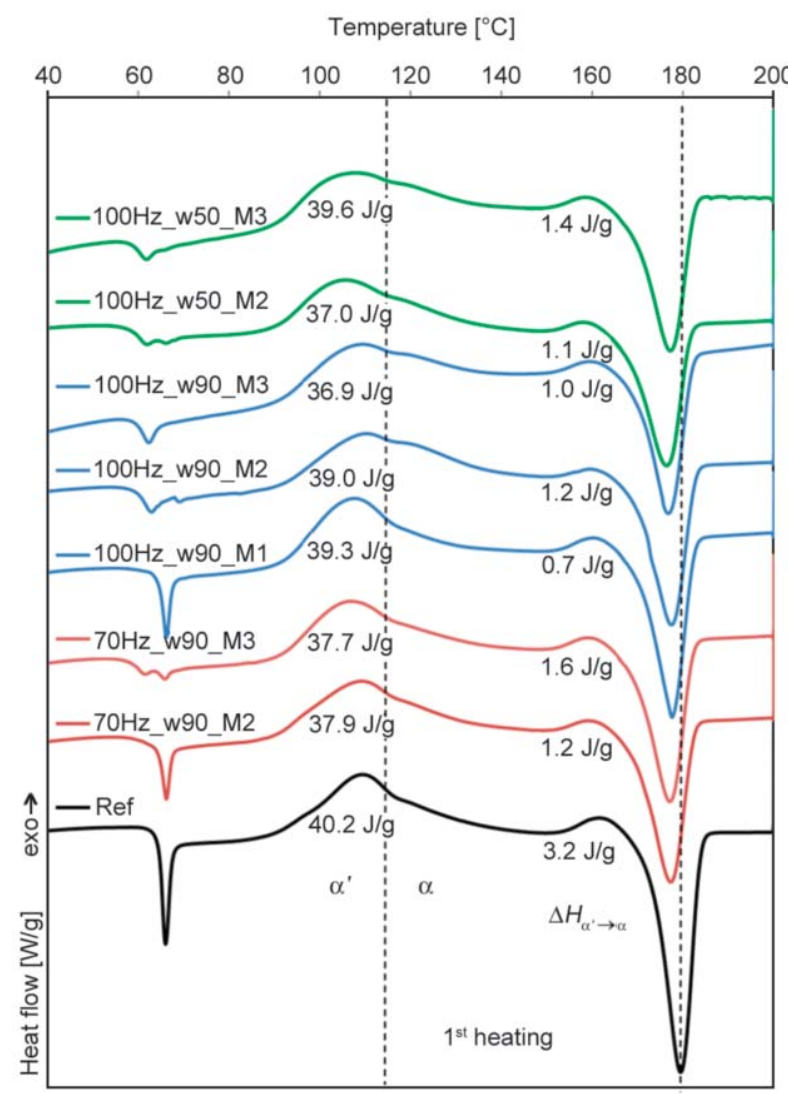

Figure 10. The first heating DSC curves of reference PLLA and micro-bars cut with a different width of the mask. 
iii. The first heating DSC curves of the reference PLLA and micro-bars of different widths cut with a laser beam width of $147 \mu \mathrm{m}$ and a repetition frequency of $100 \mathrm{~Hz}$ are presented in Figure 11a. The endothermic effect of relaxation was visible above the glass transition temperature for the reference material. This effect was eliminated due to the laser's influence in the HAZ/LAZ zone, and $T_{\mathrm{g}}$ was shifted to lower values (Figure 11b). Nevertheless, for bars width of $170 \mu \mathrm{m}$, residual relaxation effect stayed visible. Probably the small volume of material in the central part of the micro-bar has preserved its thermal history.

The shape of the curve within cold crystallization changed similarly with the increase of bar widths: the material crystallizes to a greater extent above the characteristic temperature of approximately $118^{\circ} \mathrm{C}$ than below, which was visible for the first heating cycle of the reference sample. The enthalpy of $\alpha^{\prime}-\alpha$ reorganization is correlated with the change in the material crystallized below and above $118^{\circ} \mathrm{C}$ ratio. It is worth to highlight changes in the melting of laser cut samples comparing to reference. The enthalpy of melting $\left(\Delta H_{\mathrm{m}}\right)$ was lowering with narrowing of micro-bars width, from the $43.9 \mathrm{~J} / \mathrm{g}$ for the reference PLLA to $34.7 \mathrm{~J} / \mathrm{g}$ for the narrower micro-bar $\left(100 \mathrm{~Hz} \_w 50 \_\mathrm{M} 3\right)$. All described thermal properties changes with decreasing bar width are getting stronger due to the higher share of the modified zone in analyzed bars' total volume.

In Figure $11 \mathrm{~b}$, a trend of lowering the $T_{\mathrm{g}}$ and $T_{\mathrm{m}}$ and the bar width reduction was visible. This trend indicates a gradient in the modification of thermal properties within the HAZ/LAZ zone. Based on the analysis of the DSC curves, it can be concluded that regardless of the micro-bars width, they always been under the influence of the residual heat of the cutting process, resulting in exceeding the glass transition temperature in the entire volume $\left(100 \mathrm{~Hz} \_\mathrm{w} 50 \_\mathrm{M} 3\right.$, $100 \mathrm{~Hz}$ w90_M3) or almost in the entire volume $\left(100 \mathrm{~Hz} \_w 170 \_\mathrm{M} 3,100 \mathrm{~Hz} \_w 210 \_\mathrm{M} 3\right)$ of PLLA. It cannot be determined whether the material has exceeded the $T_{\mathrm{m}}$ across the entire HAZ/LAZ, although signs of melting at the cut edges are seen in Figure 5. The analysis of DCS results and microscopic images led us to create a graphical representation of laser

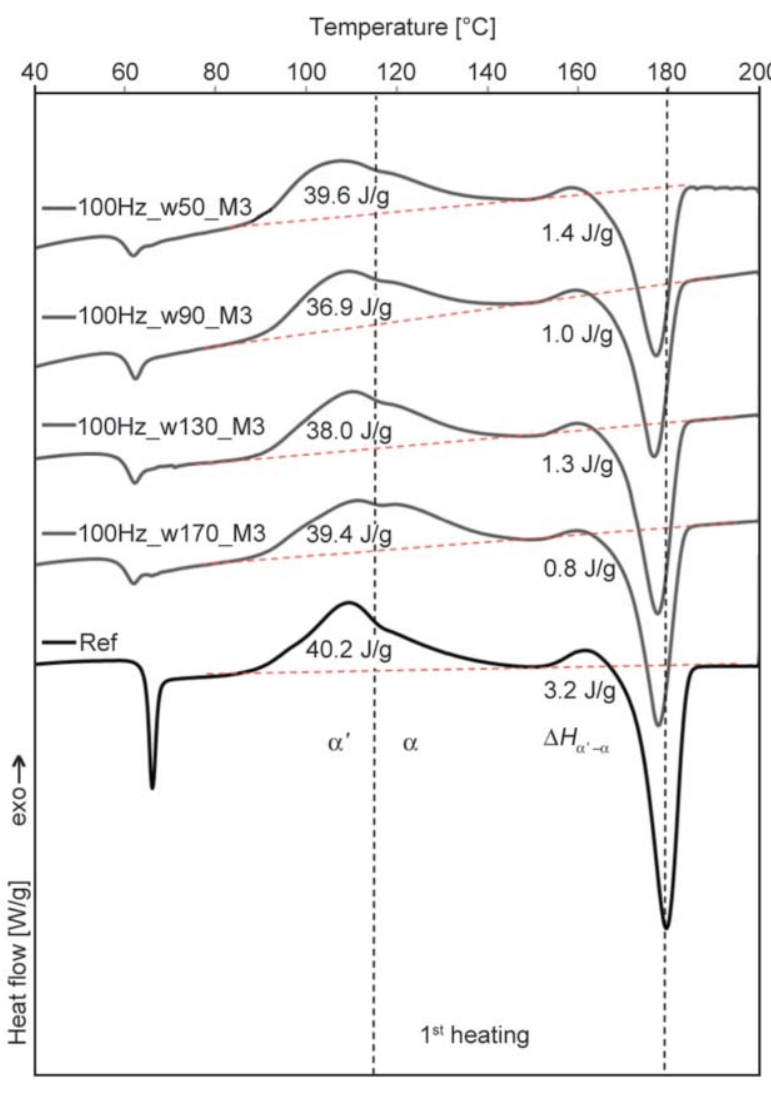

a)

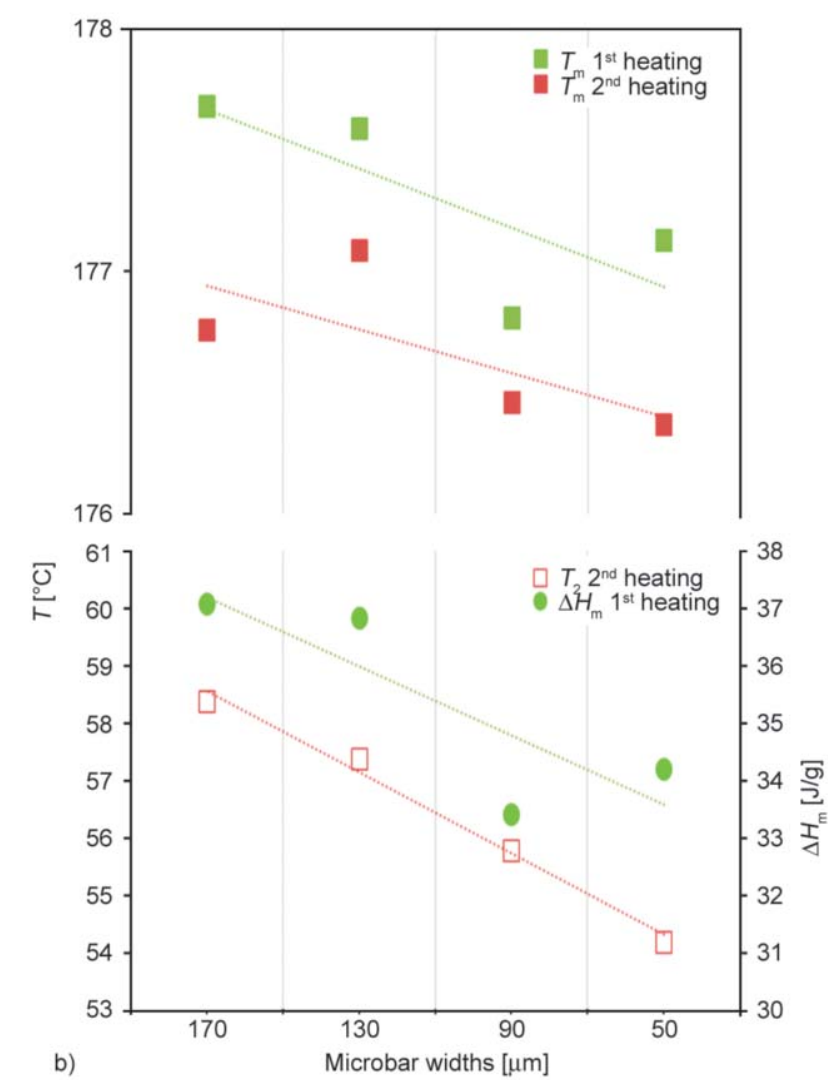

b)

Figure 11. The first heating DSC curves of PLLA samples cut to the micro-bars of different widths (a) and the evaluated glass transition and melting temperatures and melting enthalpies (the lines are guides for the eye) (b). 


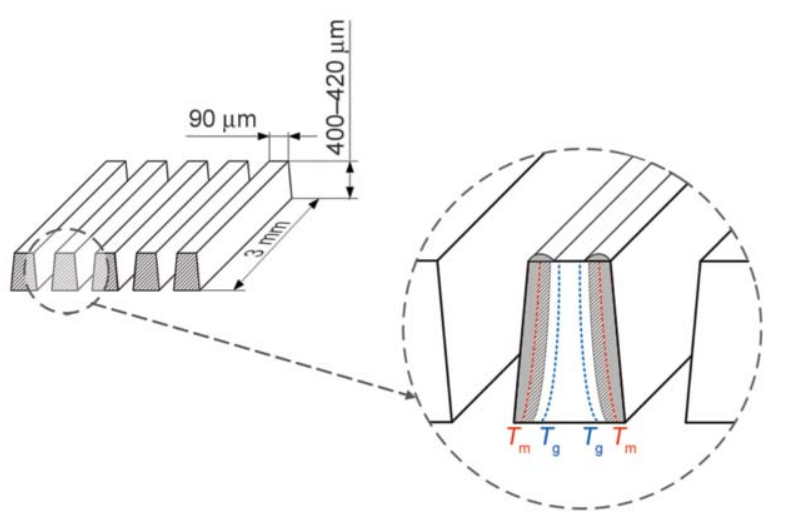

Figure 12. Graphical interpretation of temperature distribution within the laser cut micro-bars.

modification distribution within a laser cut microbars (Figure 12). We divided the regions of microstructures according to the temperature that has been reached during the laser process. We concluded that there is a layer where the melting point was reached. The molten, liquid material was also ejected on the top surface along the cut line. Then there is an intermediate zone where the temperature exceeded glass transition adjacent to melting temperature border. Moreover, DSC analyzes proved that in the core of micro-bars is always the region where the material was not heated (out of heat affected zone). This region is dominant for the samples cut with low laser repetition frequency $(50,70 \mathrm{~Hz})$ visible by no significant change in enthalpy relaxation effect at the glass transition range. It can be concluded that even the smallest micro-bars of $50 \mu \mathrm{m}$ thickness fabricated by 50 and $70 \mathrm{~Hz}$ repetition rate are free of the heat-affected zone in the meaning of heat accumulation form subsequent pulses.

The parameter window safe for the PLLA material was found for the 50 and $70 \mathrm{~Hz}$ repetition rates with M2 beam size (98 $\mu \mathrm{m}$ width) as well as for $100 \mathrm{~Hz}$ and the smallest beam width of $49 \mu \mathrm{m}$ what gives the highest cutting speed PLLA sheet. The parameter window in which residual heat accumulation is negligible is determined by product of beam width (size) and pulse repetition rate.

\section{Conclusions}

The method of the laser cutting of bioresorbable and heat-sensitive PLLA was presented. Achieved quality was satisfying for most applications like vascular stent fabrication (Figure 1) and was presented by fabrication of $50 \mu \mathrm{m}$ with bars that were smaller than used laser beam width (Figure 5). The detailed GPC and DCS analysis of fabricated micro-bars of different widths was performed for different cutting conditions (pulse repetitions rate and aperture of the laser beam) to verify the compatibility of the method with strict requirements ruling biomedical devices manufacturing. Using the DSC technique, we were able to observe even little changes in the thermal history of PLLA. Analysis of relaxation enthalpy changes connected with polymer ageing helped us evaluate the intensity of changes caused by thermal accumulation during the process. For most of the samples, we observed complete vanishing the ageing effect, which indicates that the temperature of PLLA exceeded glass transition point over the entire micro-bar. For some of the samples, enthalpy relaxation was still present in DSC curves what suggest no or negligible thermal accumulation in the laser process. In these cases, we can assume that the process parameters were optimal. We did not also observe any permanent changes in DSC curves in the second heating cycle. The decrease of melting and glass transition temperature for the sample where relaxation enthalpy was not affected indicated the possibility of photodegradation caused by scattered laser UV radiation as well as plasma radiation. This is consistent with GPC distributions where the main fraction's shift was observed for each laser cut sample. It is hard, however, to compare the degradation extent based on obtained distributions. Furthermore, it is worth to recall the small micro-bar width, which was smaller than the laser beam width. For most extreme process parameters, bimodal distribution can be observed. Nevertheless, GPC results can have a significant error as the mass of samples was low. The careful interpretation suggests that a substantial degradation of PLLA can be localized close to the walls exposed to multiple plasmas and UV exposition. As the low molecular fraction is within a thin subsurface layer, there is a potential to remove it by dissolving it in post process. The shift of weight-average molecular weight $M_{\mathrm{w}}$ of the main polymer fraction inside micro-bars after laser process is around $10 \%$, comparable with the decrease caused by the singe thermal processing cycle, which is a promising result.

Despite the observed degradation, it is worth emphasizing once again that the obtained quality (e.g. Figure 1), as well as the PLLA cutting performance comparable to femtosecond lasers (presented in separate 
studies) [15], indicate that the ArF laser may have a real and practical share in the processing of PLLA biodegradable polymers.

\section{Acknowledgements}

This study was carried out with financial support from the National Science Centre on the basis of the decision number DEC-2013/09/B/ST8/02423.

Special thanks to Prof. Teodor Gotszalk and Piotr Kunicki from Faculty of Electronics, Microsystem and Photonic Wrocław University of Science and Technology for the possibility to make SEM images.

Special thanks to dr Udo Klotzbach, Thomas Kuntze and Volker Franke from Fraunhofer IWS in Dresden for femtosecond laser cutting of PLLA.

\section{References}

[1] Turek A., Stoklosa K., Borecka A., Paul-Samojedny M., Kaczmarczyk B., Marcinkowski A., Kasperczyk J.: Designing biodegradable wafers based on poly(L-lactideco-glycolide) and poly(glycolide-co-e-caprolactone) for the prolonged and local release of idarubicin for the therapy of glioblastoma multiforme. Pharmaceutical Research, 37, 90/1-90/13 (2020).

https://doi.org/10.1007/s11095-020-02810-2

[2] Kobielarz M., Tomanik M., Mroczkowska K., Szustakiewicz K., Oryszczak M., Mazur A., Antończak A., Filipiak J.: Laser-modified PLGA for implants: In vitro degradation and mechanical properties. Acta of Bioengineering and Biomechanics, 22, 179-192 (2020). https://doi.org/10.37190/ABB-01532-2019-02

[3] Tamai H., Igaki K., Kyo E., Kosuga K., Kawashima A., Matsui S., Komori H., Tsuji T., Motohara S., Uehata H.: Initial and 6-month results of biodegradable poly-L-lactic acid coronary stents in humans. Circulation, 102, 399-404 (2000).

https://doi.org/10.1161/01.CIR.102.4.399

[4] Middleton J. C., Tipton A. J.: Synthetic biodegradable polymers as orthopedic devices. Biomaterials, 21, 2335 2346 (2000). https://doi.org/10.1016/S0142-9612(00)00101-0

[5] Hutmacher D. W.: Scaffolds in tissue engineering bone and cartilage. The Biomaterials: Silver Jubilee Compendium, 21, 175-189 (2000). https://doi.org/10.1016/B978-008045154-1.50021-6

[6] Tomanik M., Kobielarz M., Filipiak J., Szymonowicz M., Rusak A., Mroczkowska K., Antończak A., Pezowicz C.: Laser texturing as a way of influencing the micromechanical and biological properties of the poly(L-lactide) surface. Materials, 13, 3786/1-3786/13 (2020). https://oi.org/10.3390/ma13173786
[7] Kopinke F-D., Remmler M., Mackenzie K., Möder M., Wachsen O.: Thermal decomposition of biodegradable polyesters - II. Poly(lactic acid. Polymer Degradation and Stability, 53, 329-342 (1996).

https://doi.org/10.1016/0141-3910(96)00102-4

[8] Gazińska M., Krokos A., Kobielarz M., Włodarczyk M., Skibińska P., Stępak B., Antończak A., Morawiak M., Płociński P., Rudnicka K.: Influence of hydroxyapatite surface functionalization on thermal and biological properties of poly(L-lactide)- and poly(L-lactideco-glycolide)-based composites. International Journal of Molecular Sciences, 21, 6711/1-6711/21 (2020). https://doi.org/10.3390/ijms21186711

[9] Fan Y., Nishida H., Shirai Y., Tokiwa Y., Endo T.: Thermal degradation behaviour of poly(lactic acid) stereocomplex. Polymer Degradation and Stability, 86, 197208 (2004).

https://doi.org/10.1016/j.polymdegradstab.2004.03.001

[10] Kobielarz M., Gazińska M., Tomanik M., Stępak B., Szustakiewicz K., Filipiak J., Antończak A., Pezowicz C.: Physicochemical and mechanical properties of $\mathrm{CO}_{2}$ laser-modified biodegradable polymers for medical applications. Polymer Degradation and Stability, 165, 182-195 (2019).

https://doi.org/10.1016/j.polymdegradstab.2019.05.010

[11] Bartkowiak-Jowsa M., Bȩdziński R., Kozłowska A., Filipiak J., Pezowicz C.: Mechanical, rheological, fatigue, and degradation behavior of PLLA, PGLA and PDGLA as materials for vascular implants. Meccanica, 48, 721-731 (2013).

https://doi.org/10.1007/s11012-012-9626-2

[12] Carrasco F., Pagès P., Gámez-Pérez J., Santana O. O., Maspoch M. L.: Processing of poly(lactic acid): Characterization of chemical structure, thermal stability and mechanical properties. Polymer Degradation and Stability, 95, 116-125 (2010).

https://doi.org/10.1016/j.polymdegradstab.2009.11.045

[13] Stępak B., Gazińska M., Nejbauer M., Stepanenko Y., Antończak A.: Diverse nature of femtosecond laser ablation of poly(L-lactide) and the influence of filamentation on the polymer crystallization behaviour. Scientific Reports, 9, 3069/1-3069/12 (2019). https://doi.org/10.1038/s41598-019-39640-1

[14] Stępak B. D., Antończak A. J., Szustakiewicz K., Kozioł P. E., Abramski K. M.: Degradation of poly(Llactide) under $\mathrm{KrF}$ excimer laser treatment. Polymer Degradation and Stability, 110, 156-164 (2014). https://doi.org/10.1016/j.polymdegradstab.2014.08.028

[15] Antończak A. J., Stepak B. D., Gazińska M., Szustakiewicz K.: Degradation of poly(L-lactide) under femtosecond laser treatment. in 'Proceedings of SPIE, Laser-based Micro- and Nanoprocessing XII, San Francisco, USA' Vol 10520, 105201W/1-105201W/9 (2018). https://doi.org/10.1117/12.2296531 
[16] Antończak A. J., Stępak B. D., Szustakiewicz K., Wójcik M. R., Abramski K. M.: Degradation of poly(L-lactide) under $\mathrm{CO}_{2}$ laser treatment above the ablation threshold. Polymer Degradation and Stability, 109, 97-105 (2014). https://doi.org/10.1016/j.polymdegradstab.2014.07.004

[17] Agarwal S., Wendorff J. H., Greiner A.: Use of electrospinning technique for biomedical applications. Polymer, 49, 5603-5621 (2008).

https://doi.org/10.1016/j.polymer.2008.09.014

[18] Choi W. J., Hwang K. S., Kwon H. J., Lee C., Kim C. H., Kim T. H., Heo S. W., Kim J-H., Lee J-Y.: Rapid development of dual porous poly(lactic acid) foam using fused deposition modeling (FDM) 3D printing for medical scaffold application. Materials Science and Engineering C, 110, 110693/1-110693/9 (2020). https://doi.org/10.1016/j.msec.2020.110693

[19] Srithep Y., Pholharn D., Turng L-S., Veang-in O.: Injection molding and characterization of polylactide stereocomplex. Polymer Degradation and Stability, 120, 290-299 (2015).

https://doi.org/10.1016/j.polymdegradstab.2015.07.017

[20] Ortiz R., Aurrekoetxea-Rodríguez I., Rommel M., Quintana I., Vivanco M., Toca-Herrera J. L.: Laser surface microstructuring of a bio-resorbable polymer to anchor stem cells, control adipocyte morphology, and promote osteogenesis. Polymers, 10, 094902/1-094902/19 (2018).

https://doi.org/10.3390/polym10121337

[21] Stępak B., Antończak A. J., Bartkowiak-Jowsa M., Filipiak J., Pezowicz C., Abramski K. M.: Fabrication of a polymer-based biodegradable stent using a $\mathrm{CO}_{2}$ laser. Archives of Civil and Mechanical Engineering, 14, 317 326 (2014).

https://doi.org/10.1016/j.acme.2013.08.005

[22] Malinauskas M., Žukauskas A., Hasegawa S., Hayasaki Y., Mizeikis V., Buividas R., Juodkazis S.: Ultrafast laser processing of materials: From science to industry. Light: Science and Applications, 5, e16133/1-e16133/5 (2016).

https://doi.org/10.1038/1sa.2016.133

[23] Stolberg K., Friedel S., Kremser B., Roehner M.: IR and green femtosecond laser machining of heat sensitive materials for medical devices at micrometer scale. in 'Proceedings of SPIE, Laser-based Micro- and Nanoprocessing VIII, San Francisco, USA' Vol 8968, 89680E/1-89680E/11 (2014).

https://doi.org/10.1117/12.2040665

[24] Chichkov B. N., Momma C., Nolte S., von Alvensleben F., Tünnermann A.: Femtosecond, picosecond and nanosecond laser ablation of solids. Applied Physics A: Materials Science \& Processing, 63, 109-115 (1996) https://doi.org/10.1007/s003390050359

[25] Jia W., Luo Y., Yu J., Liu B., Hu M., Chai L., Wang C.: Effects of high-repetition-rate femtosecond laser micromachining on the physical and chemical properties of polylactide (PLA). Optics Express, 23, 26932-26939 (2015).

https://doi.org/10.1364/oe.23.026932
[26] Yeong W. Y., Lim K. P., Ng G. K. L., Tan L. P., Boey F. Y. C., Venkatraman S. S.: Annealing of biodegradable polymer induced by femtosecond laser micromachining. Advanced Engineering Materials, 12, B89-B93 (2010). https://doi.org/10.1002/adem.200980019

[27] Rytlewski P., Mróz W., Żenkiewicz M., Czwartos J., Budner B.: Laser induced surface modification of polylactide. Journal of Materials Processing Technology, 212, 1700-1704 (2012).

https://doi.org/10.1016/j.jmatprotec.2012.03.019

[28] Stępak B., Szustakieiwcz K., Antończak A.: Optimization of femtosecond laser micromachining of polylactide and PLLA/HAp composite. in 'Proceedings of SPIE, Laser-based Micro- and Nanoprocessing XII, San Francisco, USA' Vol 10520, 105201V/1-105201V/8 (2018). https://doi.org/10.1117/12.2296433

[29] Aguilar C. A., Lu Y., Mao S., Chen S.: Direct micropatterning of biodegradable polymers using ultraviolet and femtosecond lasers. Biomaterials, 26, 7642-7649 (2005). https://doi.org/10.1016/j.biomaterials.2005.04.053

[30] Lu Y., Chen S. C.: Micro and nano-fabrication of biodegradable polymers for drug delivery. Advanced Drug Delivery Reviews, 56, 1621-1633 (2004). https://doi.org/10.1016/j.addr.2004.05.002

[31] Stępak B., Antończak A., Szustakiewicz K., Pezowicz C., Abramski K.: The influence of ArF excimer laser micromachining on physicochemical properties of bioresorbable poly(L-lactide). in 'Proceedings of SPIE, Laser-based Micro- and Nanoprocessing X, San Francisco, USA’ Vol 9736, 97361T/1-97361T/8 (2016). https://doi.org/10.1117/12.2218380

[32] Srinivasan R., Braren B.: Ultraviolet laser ablation of organic polymers. Chemical Reviews, 89, 1303-1316 (1989).

https://doi.org/10.1021/cr00096a003

[33] Kister G., Cassanas G., Vert M., Pauvert B., Térol A.: Vibrational analysis of poly(L-lactic acid). Journal of Raman Spectroscopy, 26, 307-311 (1995). https://doi.org/10.1002/jrs.1250260409

[34] Yasuda N., Wang Y., Tsukegi T., Shirai Y., Nishida H.: Quantitative evaluation of photodegradation and racemization of poly(L-lactic acid) under UV-C irradiation. Polymer Degradation and Stability, 95, 1238-1243 (2010).

https://doi.org/10.1016/j.polymdegradstab.2010.03.034

[35] Baltazar-y-Jimenez A., Sain M.: Effect of bismaleimide reactive extrusion on the crystallinity and mechanical performance of poly(lactic acid) green composites. Journal of Applied Polymer Science, 124, 3013-3023 (2012).

https://doi.org/10.1002/app.35331

[36] Bäuerle D.: Laser processing and chemistry. Springer, Linz (2011). 
[37] Zhigilei L. V., Garrison B. J.: Microscopic mechanisms of laser ablation of organic solids in the thermal and stress confinement irradiation regimes. Journal of Applied Physics, 88, 1281-1298 (2000).

https://doi.org/10.1063/1.373816

[38] Turek A., Borecka A., Janeczek H., Sobota M., Kasperczyk J.: Formulation of delivery systems with risperidone based on biodegradable terpolymers. International Journal of Pharmaceutics, 548, 159-172 (2018). https://doi.org/10.1016/j.ijpharm.2018.06.051
[39] Hsu S-T., Tan H., Yao Y.: Effect of excimer laser irradiation on crystallinity and chemical bonding of biodegradable polymer. Polymer Degradation and Stability, 97, 88-97 (2012).

https://doi.org/10.1016/j.polymdegradstab.2011.10.006

[40] Celli A., Scandola M.: Thermal properties and physical ageing of poly (L-lactic acid). Polymer, 33, 2699-2703 (1992).

https://doi.org/10.1016/0032-3861(92)90440-8

[41] Androsch R., Schick C., Di Lorenzo M. L.: Melting of conformationally disordered crystals ( $\alpha^{\prime}$-phase) of poly (L-lactic acid). Macromolecular Chemistry and Physics, 215, 1134-1139 (2014).

https://doi.org/10.1002/macp.201400126 